working party offered no suggestions on how such an arbitration system could be established, and indeed it places the responsibility for clarification or amendment of the Act firmly on the Government. "If abortion on demand is intended," says the report, "then it is the responsibility of Government to indicate this and to amend the law and provide the services staffed by those willing to do this work."

What the report seems to imply is that the Government has two choices open to it. It can modify the Act clearly to exclude abortion for non-medical reasons, thus reducing the pressures on gynaecological services; or it can legalize abortion on demand, in which case the College would probably press for special units for all abortion work where there were no clear medical indications. "Clearly the proper staffing of special units would be essential and it was indicated to the Working Party that if special clinics were set up it would be necessary to ensure that there was full gynaecological, psychiatric, social and other services freely available to the patient," says the report, adding that even if special clinics were established within the N.H.S. there is no fundamental reason why they should be exempt from some form of payment.

The inquiry into the working of the Abortion Act under Mrs. Justice Lane ${ }^{4}$ will no doubt be reporting later this year, and it is likely to recommend some changes in the Act. This is an occasion when the Government must get its priorities right. Even if newer techniques such as using the vacuum aspiration catheter ${ }^{5}$ reduce morbidity from abortion, doctors will still support the view taken by the working party that prevention of unplanned pregnancy is far preferable to any of the possible alternative ways of dealing with it later. Unplanned and unwanted pregnancy should be a rare disaster in a society such as ours with ready access to medical advice. A determined campaign by the Government and the medical profession to make contraception understood, wanted, and available to all could well make revision of the Abortion Act quite unnecessary.

1 British Medical fournal, 1972, 1, 391

2 British Medical fournal, 1972, 1, 707

3 Unplanned Pregnancy. London, Royal College of Obstetricians and Gynaecologists, 1972, price $£ 1.00$.

4 British Medical fournal, 1971, 1, 512.

5 Lewis, S. C., Lal, S., Branch, B., and Beard, R. W., British Medical fournal, 1971, 4, 606

\section{Symposium on Glaucoma}

The publication of the First Cambridge Ophthalmological Symposium in the March issue of the British Fournal of Ophthalmology 1 on the subject of glaucoma is excuse enough to look for trends in the management of this disease. Held at St. John's College, Cambridge, in memory of Dr. Perrers Taylor, the symposium occupied two days, during which 21 papers were delivered and discussed.

Congenital glaucoma varies in severity and in its association with other ocular and somatic anomalies. Most cases fortunately respond to goniotomy, whereby the angle of the anterior chamber is opened by access across the anterior chamber by a special type of knife. When goniotomy fails the prognosis for congenital glaucoma remains poor in the long term. It would seem that the mechanism of acute or subacute glaucoma due to sudden block of the angle of the anterior chamber by the iris is well understood. It is a disease of clamant symptoms and responds well to peripheral iridectomy if the diagnosis is made early. In developed countries it should cease to be a major cause of blindness.

Glaucoma simplex is still the problem which defies solution. Insidious and symptomless in onset, it affects people in middle age. Genetically it is multifactorial, and the pattern of heredity is therefore not Mendelian though often familial. The cause of raised intraocular pressure would appear to lie in the trabecular meshwork on the inner side of the canal of Schlemm. The intimate nature of this obstruction is still something of a mystery, though intracellular vacuoles in the canal endothelium play some part in transport of aqueous from the anterior chamber into the canal in healthy eyes.

The introduction of the applanation tonometer and a method of measuring outflow by indentation tonometry were promising in the early 1960s as methods of assessment. Since then surveys have shown that raised pressure and low outflows are not synonymous with the syndrome of simple glaucoma. Tonography has proved a disappointing clinical test because prolonged pressure on the eye leads to the expression of both blood and aqueous, and the unknown proportion of each in any given test produces results which are unreliable as a measure of aqueous outflow. Provocative tests and steroid-induced hypertension have failed to produce clear diagnostic criteria in doubtful cases and have added little to our understanding of frank examples of the disease. What is still required is a clinically applicable quantitative method of determining the relationship between tension and loss of visual field in the individual patient. Meanwhile the time-honoured method of holding the intraocular pressure below $21 \mathrm{~mm} \mathrm{Hg}$, round the clock, if possible by medical treatment, still stands as the orthodox form of management.

Medical therapy includes miotics to contract the pupil. Because of the myopia induced they are particularly disabling for the patient who has an active accommodation. Epinephrine in combination with guanethidine bids fair to act as an alternative to miotic therapy because of the absence of side effects and the tension-lowering properties of the two drugs acting synkinetically. Surgery for glaucoma is also on the move, chiefly owing to the introduction of the operating microscope, which makes attacks on the canal of Schlemm itself feasible. Trabeculotomy, whereby the canal is entered and its inner wall is ruptured (or Barkan's membrane is ruptured) is now a popular procedure, particularly for congenital glaucoma when goniotomy fails. Trabeculectomy, wherein part of the canal is excised so that its open ends are exposed to the anterior chamber, is gaining adherents. It functions possibly as a drainage operation with an exit well away from the limbus, but this site in itself has distinct advantages particularly in the avoidance of a cystic avascular bleb and the risks of postoperative infection.

The striking feature of the symposium was the renewed interest in the optic nerve-head-its blood supply, its vascular response to raised intraocular pressure, its appearance in the fluorescein angiogram, and its varying configuration in health and disease. It was even suggested by one contributor that changes at the disc head are of prime importance as a guide to diagnosis and progression. The obsession with ocular hydrodynamics which filled the minds of most ophthalmologists interested in glaucoma for many years appears to be lifting and an atmosphere of release pervaded a stimulating meeting.

\footnotetext{
1 British fourmal of Ophthalmology, 1972, 56, Pt. 3.
} 